\section{Organizing ERP research: a knowledge-centric approach}

\section{Organizing ERP research}

Farzaneh Amani and Adam Fadlalla Accounting and Information Systems Department, Qatar University, Doha, Qatar

\begin{abstract}
Purpose - The purpose of this paper is to gain insight into enterprise resource planning (ERP) research by framing ERP intellectual contributions using a knowledge-centric taxonomy that was originally proposed as an organizing framework for classifying conceptual contributions in marketing. Thus the paper provides a better understanding of existing gaps and future opportunities in ERP research.

Design/methodology/approach - Using MacInnis framework, the authors classified a sample of 300 ERP articles published during the period 2000-2014 into a topology of four generic contributions types and eight sub-types.

Findings - The findings indicate that whereas the explicating type received the most attention by researches, the debating type received the least. It also seems that there is a temporal dimension to the different types of conceptual contributions. Identification of usefulness of the ERP systems to business was not addressed as would have been predicted by the build-evaluate lens of March and Smith framework.

Research limitations/implications - The main limitation of this research is that only used articles from scholarly journals, and did not include conference proceedings, books, and other outlets. Another limitation is that the search criteria was title-based, which may have missed some relevant papers. Research implications include highlighting the importance of a knowledge-centric view of ERP research, and practical implications include the call for robust measurement criteria for ERP benefits and rigorous ERP comparison schemes.

Originality/value - The main contribution is providing an alternative approach to framing the ERP intellectual contributions. The proposed taxonomy revealed major areas of focus and opportunities for future ERP research emphasis. To the best of the authors' knowledge, this is the first instantiation of MacInnis framework into ERP research.
\end{abstract}

Keywords Literature review, Enterprise resource planning (ERP), Intellectual contributions, MacInnis framework

Paper type Research paper

\section{Introduction}

Enterprise resource planning (ERP) systems are highly complex information systems (IS) that enable achievement of integration of information flow and business processes. These systems support business operations and functions by providing real time data which have been collected, processed, updated, and stored in an integrated database. There are many benefits that companies realize through transforming their old un-integrated systems to ERP systems; including reduction of cycle time, faster processing of information, enablement of e-commerce, better information and knowledge management (KM), improved reporting, (Davenport, 2000; Ross and Vitale, 2000), providing a unified view of business enterprise by combining all functions and departments together with integrated and unified database for data collection, processing, monitoring, and reporting (Al-Mudimigh et al., 2001; Dillon, 1999; Davenport, 2000; Murray and Coffin, 2001), reliable information access (Murray and Coffin, 2001), avoidance of data and operation redundancy, cost reduction (Mandal and Gunasekaran, 2003; Wu and Wang, 2007) through improved control by enterprise-wide analysis of organizational decisions, easy adaptability to changes in business processes, improvement in scalability
Received 22 September 2015

Revised 1 December 2015

13 February 2016

12 March 2016

Accepted 15 March 2016

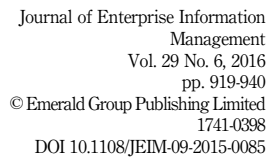


JEIM 29,6

920

and maintenance, global outreach via extended modules such as customer relationship management (CRM) and supply chain management (SCM), and e-business (Hossain et al., 2002).

For organizations looking for reaping ERP benefits there are critical success factors (CSFs) to ensure a successful implementation. Successful ERP implementation requires clear strategic ERP goals and business justifications, excellent project management, well-planned business process reengineering (BPR), extensive user education and training, change management, carefully formed implementation team, data quality assurance, and clear ERP performance measures (Hong and Kim, 2002; Murray and Coffin, 2001; Ross and Vitale, 2000; Scott and Vessey, 2000; Umble et al., 2003). Skok and Legge (2002) suggested that four key CSFs are necessary for successful ERP projects implementation; namely, managing cultural and business change, managing consultants, managing conflicts, and managing staff retention - this is especially true given the high complexity of ERP projects. Skok and Legge (2002) provided differentiating factors of ERP projects implementation complexity:

- the number and variety of stakeholders in any project implementation;

- the high cost of implementation and consultancy;

- the level of integration of business functions;

- the extent of configuration of software representing core processes;

- the management of change and political issues associated with BPR projects; and

- the requirement for enhanced user training and familiarization.

Implementing ERP systems is associated with many challenges that need to be addressed carefully for ERP to work as intended. Examples of these challenges include selecting an appropriate plan for end-user education, ensuring a global compatibility and flexibility of ERP, ensuring top management commitment for streamlining the decisions related to integration of business processes, and meeting an aggressive time line (Gupta, 2000; Hong and Kim, 2002; Ross and Vitale, 2000; Scott and Vessey, 2000). Furthermore, enterprise systems require huge investment of money where it cost millions of dollars for acquiring and additionally millions of dollars in installing, training, and consulting (Volkoff, 1999), and vendor selection involves many considerations including investment in $\mathrm{R} \& \mathrm{D}$, long-term commitment to the product and services, extended ERP capabilities, add-on modules such as CRM and SCM (Hossain et al., 2002).

There are many problems of implementing ERP systems, such as time-consuming consensus building to adopting an ERP system, high resistance to BPR, many times lack of fit of the ERP modules not only to the business processes, but also to the culture and the strategic goals of the company, risk of vendor dependence, difficulty of balancing features and complexity, and the need for scalability and global outreach.

Due to all of the aforementioned ERP benefits, organizations embraced integrated solutions provided by ERP systems. Given their strategic significance, it is not surprising that ERP systems received great attention from researchers, academics and practitioners alike. The published ERP journal articles represent a form of contribution by researchers and practitioners to further the realization of benefits derived from ERP systems, and/or reduction of ERP implementation costs and risks. Classifying the contributions made by ERP researchers is of great importance in shedding light on the coverage that exists in ERP research and the gaps that require more attention by 
researchers and practitioners. Intellectual advances are key to the vitality of ERP research as they play an important role along the discovery-justification continuum (Yadav, 2010) that characterizes the knowledge development process. This paper aims at uncovering and classifying ERP research captured in journal articles published during the period 2000-2014, using MacInnis framework to identify gaps and propose directions for future research. MacInnis framework provides a systematic view of the process by which knowledge evolves. In particular, as concisely stated by MacInnis, "knowledge begins when something new is first identified. Research advances by efforts to delineate it. Through delineation, complexities are realized that, in turn, require differentiation, which ensues from deeper thinking. Clarity from differentiation gives way to agreed-on views that are advocated and seem true. Subsequent thought may give way to a revised perspective, with summarized views on the revised view giving way to integrated perspectives. Refutations of the integrated view give rise to the identification of novel ideas." Thus this paper uses MacInnis framework since it is simple, yet provides a powerful lens to examine progress and advancement in ERP research.

The remainder of this paper is organized as follows. Section 2 presents a review of the relevant literature. Section 3 describes the research methodology. Section 4 reports and discusses the results of the study, and finally Section 5 draws some conclusions, presents limitations, and future directions.

\section{Literature review}

In this section, we focus on previous literature review papers. Many researchers attempted to organize the intellectual contributions of ERP research. An early such attempt is that of Esteves and Pastor (2001), who provided an annotated bibliography of ERP publications in the main IS journals and conferences during the period (19972000). They surveyed and categorized 189 papers (including only 21 journal articles) based on the ERP lifecycle phases. This early attempt of classification has the drawback of being restricted to only IS journals and it covered only a short three-year period and a limited number of journal articles.

Shehab et al. (2004) performed a comprehensive literature review covering the period (1990-2003) with the goal of identifying gaps that need more attention by researchers and practitioners and helping making decisions concerning ERP selection and implementation. They used 76 (72 percent of which were journal articles) citations on ERP systems (including books, conference papers, and journal papers) and examined three main areas: the main vendors of ERP systems, the ERP selection criteria, and the ERP implementation including approaches to implementation and factors affecting the implementation process. Their results indicated the need for advanced costing techniques in ERP environments, the need to develop new techniques for adapting ERP systems to the specific needs of the organization, the need to adapt to the new trends of web-based procurement with outsourcing of ERP applications. However, Shehab et al. (2004) reviewed only three aspects of the ERP systems and did not consider other critical aspects.

Cumbie et al. (2005) examined only 49 ERP journal articles published mainly in eight IS journals and seven operations management (OM) journals during (1999-2004). They categorized these articles based on the content (such as topic and focus) and processes (such as methods). Cumbie et al. (2005) indicated that ERP articles have increased during the five years period, ERP articles were published more in the IS journals than in OM journals, and that many research methods were either under-represented or 
JEIM 29,6

absent. They analyzed these publications in three areas: 28 focused on implementation, 14 on operation, and 7 on benefits. The authors aimed at identifying the gaps that exist and need to be closed, particularly the need to analyze ERP within the context of the supply chain. The limitation of Cumbie et al. (2005) review is the restriction to only IS and OM journals and the lack of overview of ERP research field.

Botta-Genoulaz et al. (2005) analyzed and classified ERP research papers published during the period 2003-2004 based on six categories: implementation of ERP, optimization of ERP, management through ERP, the ERP software, ERP for SCM, and case studies for the purpose of identifying the new trends in ERP research literature. Based on their survey of 80 articles (including 17 conference papers) they showed there is growing interest on the following ERP topics: the post-implementation phase of the ERP projects, the customization of ERP systems, the sociological aspects of the ERP implementation, the interoperability of the ERP with other systems, and the return on investment of the ERP implementations. The drawback of their classification was the focus on the message of the articles themselves instead of highlighting the actual value of the contributions made. In addition, their survey focused only on providing a snapshot about ERP research during the years 2003 and 2004.

Esteves and Bohorquez (2007) examined 460 of ERP publications form 23 IS journals and ten IS conference papers in an attempt to update the annotated ERP bibliography published in 2001 by Esteves and Pastor. They examined papers published during (2001-2005) and classified them according to an ERP-lifecycle-based framework that is structured in phases. They categorized the publications based on the topic not the methods to seven different categories. In total, 25 publications focused on adoption, 15 on acquisition, 207 on implementation, 68 on usage, 59 on evolution, 0 on retirement, 35 on education, and 40 as general which are papers not related to the ERP lifecycle. They showed that ERP research was still mainly focusing on the implementation phase of the ERP lifecycle and there are clear gaps in ERP research relating to the SMEs market. Esteves and Bohorquez (2007) update still focused on ERP research from the IS journals perspective.

Moon (2007) examined 313 ERP journal papers for the period Jan 2000-May 2006 and classified the literature based on six major themes with nine-sub themes with the aim of providing researchers an understanding of what kind of questions have been addressed, the gaps that exist, and providing a bibliography of published articles. Moon used different themes than those used by Botta-Genoulaz et al. (2005) Moon's themes are implementation, using ERP, extension, value, trends, and education. Moon found that education of ERP is one of the promising areas and that there were few articles that addressed the status of ERP education with international collaboration. Moon's classification scheme is subjective and does not cover all aspects of ERP systems.

Aloini et al. (2007) examined ERP literature from risk management perspective in ERP introduction with an attempt of analyzing the risk factors involved. They analyzed 75 articles and categorized them in to four groups: ERP selection, ERP implementation, ERP risk management, and general ERP projects. They classified these articles again based on a second dimension involving research type and methods. The research type and methods dimension includes three groups: a conceptual/ theoretical group, with primary focus on development of models, concepts, or ideas; an empirical group, with primary focus on surveys, case studies, interviews or anecdotal information; and a mix group of empirical and conceptual/theoretical methods. They reached the same conclusion as previous researchers that ERP implementation is the 
most discussed theme, namely, in 58 percent of the articles, followed by ERP selection (in around 17 percent of the articles). In addition, they also found that the majority (48 percent) of the contributions used the conceptual/theoretical-empirical mix research type. Aloini et al. (2007) also found that there was an increase of emphasis on the discussion of ERP periphery themes and not on the ERP systems themselves. For example, implementation methods, organizational impact, and comment on case studies are typical subjects of studies.

Schlichter and Kraemmergaard (2010) conducted a comprehensive literature review of 885 ERP peer-reviewed articles for the period of 2000-2009. They classified the ERP publications based on journal, authors, year of publication, research discipline, research topic, and research methodologies. They indicated that ERP academic knowledge has reached certain maturity. They reported that ERP implementation was the most researched topic (30 percent of the papers), followed by ERP optimization (20 percent of the papers). OM was the most researched ERP discipline (31 percent of the papers), followed by IS (24 percent of the papers). They also found that case studies were the most method used ( 22 percent of papers) followed by surveys (15 percent of the papers). Schlichter and Kraemmergaard found seven areas of concern in ERP research: implementation, post-implementation, organizational change and managerial implications, ERP market and industry, education and training, SCM, the ERP system itself - all of which are issues that have implications for both managers and researchers.

The classifications provided by previous ERP researchers either used no frameworks (Esteves and Pastor, 2001), or mostly used self-developed frameworks (Shehab et al., 2004; Cumbie et al., 2005; Botta-Genoulaz et al., 2005; Esteves and Bohorquez, 2007; Moon, 2007; Aloini et al., 2007). Only Schlichter and Kraemmergaard (2010) used a literaturebased ERP literature classification framework. However, Schlichter and Kraemmergaard (2010) framework is based on ERP literature (Table I). To address this gap of narrowly focused ERP literature classification, we adopt the framework originally proposed by

\begin{tabular}{|c|c|c|c|}
\hline Author(s) & Classification criteria & $\begin{array}{l}\text { Basis of } \\
\text { classification }\end{array}$ & \\
\hline $\begin{array}{l}\text { Esteves and Pastor } \\
\text { (2001) }\end{array}$ & None & $\mathrm{n} / \mathrm{a}$ & \\
\hline Shehab et al. (2004) & Vendors, selection criteria, and implementation & IS literature & \\
\hline Cumbie et al. (2005) & Content (topic and focus) and processes (methods) & IS literature & \\
\hline $\begin{array}{l}\text { Botta-Genoulaz et al. } \\
(2005)\end{array}$ & $\begin{array}{l}\text { Implementation, optimization, management, the software, } \\
\text { supply chain management and case studies }\end{array}$ & IS literature & \\
\hline $\begin{array}{l}\text { Esteves and } \\
\text { Bohorquez (2007) }\end{array}$ & $\begin{array}{l}\text { ERP-lifecycle-based framework: adoption, acquisition, } \\
\text { implementation, usage, evolution, retirement, education, } \\
\text { and general }\end{array}$ & IS literature & \\
\hline Moon (2007) & $\begin{array}{l}\text { Implementation, using ERP, extension, value, trends, and } \\
\text { education }\end{array}$ & Self-developed & \\
\hline Aloini et al. (2007) & $\begin{array}{l}\text { Two dimension: first dimension: ERP selection, } \\
\text { implementation, risk management, and general ERP } \\
\text { projects; second dimension: research type and methods }\end{array}$ & IS literature & \\
\hline $\begin{array}{l}\text { Schlichter and } \\
\text { Kraemmergaard (2010) }\end{array}$ & $\begin{array}{l}\text { Methods: case study(ies), archival, theoretical, survey, } \\
\text { experiment, descriptive, design science, combined and } \\
\text { not mentioned; topic: implementation, optimization, } \\
\text { management, the ERP tool, SCM, studying ERP, education, } \\
\text { the market and industry, and others }\end{array}$ & IS literature & $\begin{array}{r}\text { Table I. } \\
\text { Summary of } \\
\text { previous ERP } \\
\text { literature review } \\
\text { research }\end{array}$ \\
\hline
\end{tabular}

Organizing
ERP research

923 
JEIM

29,6

924

MacInnis (2011) to organize conceptual contributions in marketing and apply it to the ERP research. We believe that using frameworks from outside the ISs discipline to classify ERP intellectual contributions will broaden and enrich our understanding of the ERP literature. For example, MacInnis' framework provides a more knowledge-centric approach to the ERP research classification rather than an ERP lifecycle-centric classification. This approach provides us with insights into the intellectual contributions at a higher and more macro level than the previous system-based or discipline-based approaches. Furthermore, this knowledge-centric approach is domain independent and may be applied to any research topic or discipline, and, in the case of ERP, provides a different lens to view the research.

\section{Methodology}

\subsection{Data}

A total of 543 ERP journal articles published in 141 different journals during the period 2000-2014 were identified using the inclusion-exclusion criteria described in Table II. Due to the labor-intensive requirements for classifying the papers into the types and sub-types of MacInnis contributions, a sample of 300 articles, from 80 journals, was selected from the 543 papers for manual classification by the authors into the four generic contributions types proposed by MacInnis; namely, envisioning, explicating, relating, and debating. The 300 papers were selected such that all years are represented and within each year at least 50 percent of the journals in that year are represented. Each of the authors classified each article into one of the generic types, and then compared their classifications. When there is a disagreement in classification, the authors scrutinized the paper in question together and came to a consensus on the final classification. Similarly, the authors classified the sample articles into the more specific sub-types within the broader generic types: identifying and revising for envisioning, delineating and summarizing for explicating, differentiating and integrating for relating, advocating, and refuting for debating. Some papers may be classified into more than one category, in which cases; the paper was classified by the authors into the category that fits the overarching theme and the main contribution of the paper. For example, Tsai et al. (2012) can be classified as relating since it relates ERP selection criteria and ERP systems success, but can also be classified as identifying since its main contribution is the identification of the exact selection criteria that lead to system

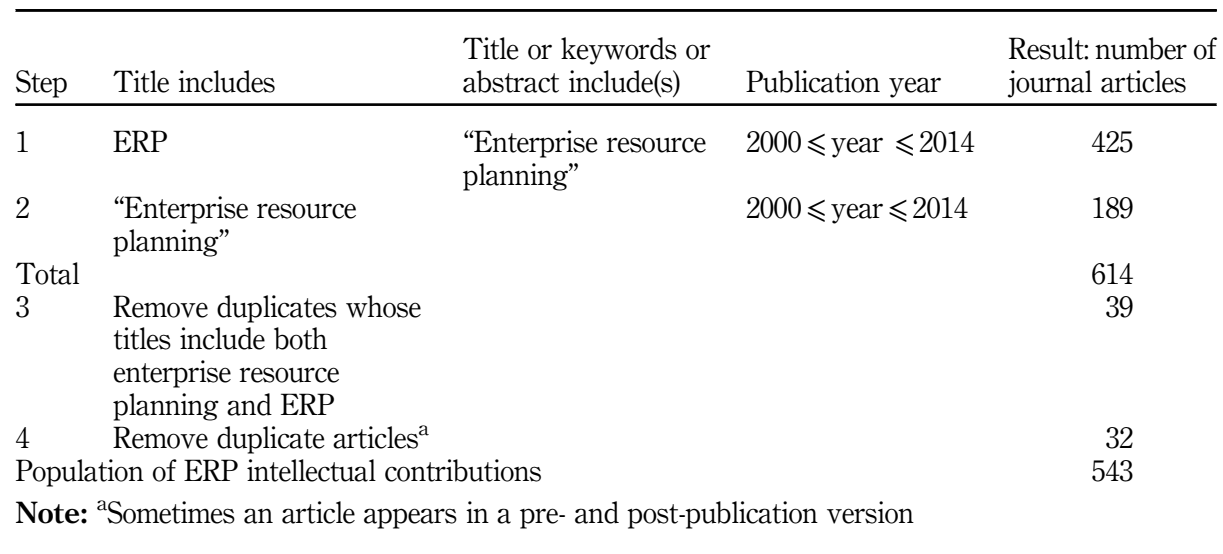

Table II.

Inclusion-exclusion criteria for selecting ERP papers
Population of ERP intellectual contributions

32

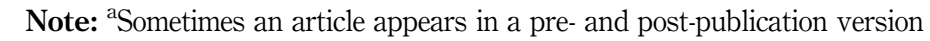


success; hence it was classified as the latter type. In general, we believe McInnis framework is easily applicable as it uses a well-defined set of intellectual contribution types and sub-types that can readily be used to classify literature in many domains not just marketing or ERP.

\subsection{MacInnis framework}

MacInnis (2011) developed a framework for organizing conceptual contributions in marketing. The framework mainly aims at achieving four objectives defining conceptualization, identifying the entities to which conceptualizations apply, what types of conceptual contributions academic scholarship can make, and what criteria should be used to evaluate the quality of conceptual ideas. The framework divides conceptual contributions in marketing to a typology of four generic types: envisioning new ideas, explicating ideas, relating ideas, or debating ideas. Envisioning encompasses contributions that add to the process of discovery by identifying something new, and also encompasses contributions that add to the process of justification by using new information, facts, or observations to revise an existing idea. Explicating involves detailing, charting, describing, or depicting an entity and its relationship to other entities and to encapsulate, digest, reduce, or consolidate. Relating involves seeing types of things and how they are different, to discriminate, parse, or see pieces or dimensions that comprise a whole, and to see previously distinct pieces as similar, often in terms of a unified whole whose meaning is different from its constituent parts as well as to synthesize, amalgamate, or harmonize. Debating involves endorsing or refuting a way of seeing. Each of these generic types is further subdivided into two distinct sub-types: identifying and revising as sub-types of envisioning, delineating and summarizing as sub-types of explicating, differentiating and integrating as sub-types of relating, and advocating and refuting as sub-types of debating. The framework also provides the evaluative criteria on how to judge each type of conceptual contribution. Table III provides descriptions of these types of contributions and their execution and interestingness evaluative criteria.

\section{Analysis and discussion}

\subsection{Overall research findings}

The initial finding is that 51 percent of the analyzed articles belong to the explicating contribution type, 30 percent belong to the envisioning contribution type, 14 percent belong to relating, and 5 percent belong to debating (Figure 1). There is a wide variation in the coverage of ERP topics in the literature, and there is a clear gap in the coverage of the relating and the debating types compared to that of the explicating and the envisioning types. The high percentage of explicating papers is probably a reflection of the high level of complexity of ERP systems and their multidimensionality, including their selection, adoption, justification, benefits, and impact, and thus the need for a clear understanding of these dimensions for a successful ERP implementation. The low coverage of relating in the ERP literature seems to be a direct consequence of the uniqueness of these systems as they are not like any other existing IS in terms of their significance, cost, complexity, and potential. On the other hand, it appears that there is some kind of overall consensus between researchers' conceptualizations of ERP systems, whether these conceptualizations were positive (advocating) or negative (refuting); and hence the low coverage of debating. This is consistence with MacInnis findings, and possible explanations may include hesitation by authors to avoid
Organizing ERP research 
Generic types

of conceptual contributions and their sub-types Meaning

Evaluative criteria based on execution

Evaluative criteria based on interestingness

\section{6}

\section{Envisioning Conceiving a new idea}

Identifying To see that something exists; to apprehend, notice, or behold

Make us aware of what we What is unseen is seen;

have been missing and why what is unobservable is it is important; reveal what observable; what is new questions can be addressed

Revising

To see something that has been identified in a new way

Identify why revision is necessary; reveal the advantages of the revised view and what novel insights it generates; maintain parsimony

Explicating Articulating, explaining ideas Delineating To detail, chart, describe, or depict an entity and its relationship to other entities

Describe what the entity is,
why it should be studied, and how it works (e.g. its antecedents, processes, moderating factors); provide a roadmap for future research

Summarizing To see the forest for the trees; to encapsulate, digest, reduce, or consolidate

Circumscribe what falls within and outside the scope of the summary; develop an organizing framework; provide clear, accurate, and relevant conclusions; simplify through reduction; develop research priorities

Relating Seeing how wholes and parts are related

Differentiating To see types of things and Indicate how entities are how they are different; to discriminate, parse, or see pieces or dimensions that comprise a whole

different and why differentiation matters; indicate what novel insights can be gleaned or what findings can be reconciled from differentiation

Integrating To see previously distinct pieces as similar, often in terms of a unified whole Accommodate extant knowledge; explain puzzling or inconsistent whose meaning is different findings; reveal novel from its constituent parts; insights; create parsimony to synthesize, amalgamate, or harmonize unknown is known; what does not matter, matters a great deal What is seen, known, observable, or known can be seen differently what is holistic is particularistic

What is complex is simple; what is macro is micro; what is unrelated is related; what is particularistic is holistic

What is similar is different; what is inseparable is separable; what is organized is disorganized; what is one dimensional is multidimensional; what is homogeneous is heterogeneous What is different is similar; what is separable is inseparable what is disorganized is organized; what is multidimensional is one dimensional; what is heterogeneous is homogeneous

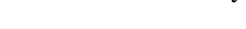

Table III.

MacInnis' conceptual contributions framework - types of contributions, their execution, and interestingness evaluative criteria 
Generic types

of conceptual

contributions

and their

sub-types

Meaning

Debating

Advocating

Putting forward reasons designed to convince others about the validity of an idea

To endorse a way of seeing; Clearly state the issue and to support, justify, or suggest an appropriate path
Refuting

To rebut a way of seeing; to challenge, counter-argue, contest, dispute, or question one's perspective on that issue; state premises and assumptions; provide credible and unambiguous evidence; draw conclusions that support the advocated view; avoid fallacious reasoning errors

Clearly state the issue and one's perspective on that issue; state premises and assumptions; provide credible and unambiguous evidence; draw conclusions that are consistent with the refuting view; avoid fallacious reasoning errors

\section{Organizing ERP research}

Evaluative criteria based on interestingness is unacceptable is acceptable; what is wrong is right; what is inappropriate is appropriate

What is true is false; what is acceptable is unacceptable; what is right is wrong; what is appropriate is inappropriate

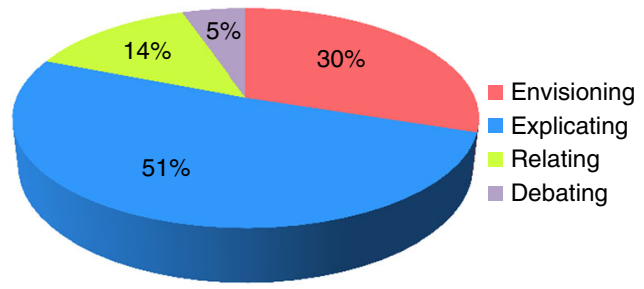

Notes: The majority (51 percent) belongs to explicating, 30 percent to envisioning, 14 percent to relating, and 5 percent to debating
Figure 1. Distribution of the 300 sample ERP articles over the four types of conceptual contributions

subjecting their own work to debating if they debate other people's work. Including intellectual contributions such as conference proceedings and other types may lead to somewhat different distribution of coverage.

An interesting observation is that it appears there is a temporal dimension to the various types of intellectual contributions. For example, examining the total intellectual contributions of the various types over three consecutive five-year blocks (2000-2004, 2005-2009, and 2010-2014) (see Table IV), we observe that the explicating and the relating types exhibit an upward trend, while envisioning and debating are showing significant drops during the last interval (2010-2014). It is logical that researchers start with envisioning a scientific phenomenon which is then followed by explicating (particularly if the subject of discussion is complex, such as the case of ERP systems), 
JEIM

29,6

928

then the contributions move to a higher level of discourse, namely, relating the concept to other concepts, and possibly, concurrently to, or following relating, the discourse moves to debating the value of the topic that has been envisioned, explicated, and related. For example, ERP contributions associated with envisioning and explicating discussed extensively in the very early years (2000-2004) of the selected time frame for this research (2000-2014). On the other hand, relating seems to be tackled by researchers more extensively at later times (2005 and beyond). It is also interesting to note that identifying, delineating, and summarizing are persistently discussed throughout the years, whereas revising, differentiating, integrating, advocating, and refuting are discussed in an intermittent manner.

\subsection{Envisioning ERP contributions}

Identifying topics discussed by ERP researchers include topics such as: managerial aspects, such as, identifying the impact of business vision, top management support, and external expertise on ERP success, impact of individual differences on ERP training programs, and impact of leadership style on team cohesiveness and performance during ERP implementation, selection, adoption, and implementation aspects of ERP systems, such as, identifying ERP selection criteria, impediments to implementation, CSFs, customization choices, measures to assess ERP adoption in SMEs, barriers preventing SMEs from harnessing ERP systems, benefit, satisfaction, and competitive advantage, such as, user satisfaction in ERP projects, variables contribute to ERP competitive advantage, and risk and uncertainty, such as, risks affecting ERP post-implementation, and uncertainty and contingency plans in ERP-controlled manufacturing environments (ERP intellectual contributions: envisioning type):

(1) Identifying (24 percent)

- Sample of topics:

- Managerial aspects: identification of role of e-learning in ERP training (Choi et al., 2007). Identification of impact of individual differences on ERP training programs and continuance intention (Chou and Chen, 2009). New dimensions of managerial intervention in the ERP implementation (Osei-Bryson, et al., 2008). Identifying the impacts of leadership style on team cohesiveness and performance during ERP implementation (Wang et al., 2005). Impacts of business vision, top management support, and external expertise on ERP success (Ifinedo, 2008). Impact of team attributes on ERP adoption (Rothenberger et al., 2010). Identifying the impacts of the ERP on power structure between management and workers (Sia et al., 2002).

- Selection, adoption, and implementation: identification of ERP selection criteria (Baki and Cakar, 2005; Karsak and Özogul, 2009; Tsai et al., 2012).

Table IV.

ERP Intellectual contributions of the various types over three consecutive five-year time intervals

\begin{tabular}{lcccc}
\hline & Envisioning & Explicating & Relating & Debating \\
\hline $2000-2004$ & 22 & 35 & 8 & 7 \\
$2005-2009$ & 42 & 57 & 14 & 7 \\
$2010-2014$ & 26 & 61 & 19 & 2 \\
Total & 90 & 153 & 41 & 16 \\
\hline
\end{tabular}


Factors impacting ERP implementation (Upadhyay et al., 2011). Identification of impediments to implementation of ERP systems (Kim et al., 2005). Identifying maintenance activities pertaining to ERP implementation (Nah et al., 2001; see Pui Ng et al. (2002). Identifying ERP customization choices (Parthasarathy and Sharma, 2014). Identifying the ERP strategic and operational requirements for SME's (Huin, 2004). Measures to assess ERP adoption in SMEs (Shiau et al., 2009). Identification of ERP CSFs (Amid et al., 2012; Françoise et al., 2009; Zhang et al., 2005) in ERP research SMEs (Doom et al., 2010; Sun et al., 2005; Snider et al., 2009).

- Benefit, satisfaction, and competitive advantage: determining user satisfaction in ERP projects (Longinidis and Gotzamani, 2009; Saatçioglu, 2009). Identifying CSFs contributing to toward ERP II benefits realization (Norton et al., 2013). Indentifying variables contribute to ERP competitive advantage (Beard and Sumner, 2004) in SMEs (Koh and Simpson (2005). Identification of causes influencing the effectiveness of the post-implementation ERP systems (Yu, 2005). Identifying causes of ERP failures (Vogt, 2002). Investigating ERP failure in a developing country (Hawari and Heeks, 2010).

- Risk and uncertainty: developing a support system to automatically adjust ERP systems to environmental changes (Kwon and Lee, 2001). Developing risk treatment strategies and actions during the introduction of ERP systems (Aloini et al., 2012a). Identifying risks affecting ERP postimplementation (Pan et al., 2011). Risk assessment in ERP projects. Managing risks impacts on ERP performance (Lopez and Salmeron, 2014; Wu et al., 2008). Identifying uncertainty and contingency plans in ERPcontrolled manufacturing environments (Koh et al. (2006).

(2) Revising (6 percent)

- Sample of topics:

- Revising ERP implementation using a KM perspective (Chan et al., 2009; Pan et al, 2007). Revising of ERP implementations from the perspective of globalization side effects (Hanseth et al., 2001). Revising ERP implementation success in post-implementation organizational contexts (Ifinedo, et al., 2010). Revising ERP implementation success from project environment perspective (Dezdar and Ainin, 2011). Expanding ERP implementations to include VAT compliance (Goossenaerts et al., 2009). Improving MRP part explosion in an ERP environment (Lee et al., 2007). Evaluating ERP performance from balanced scorecard approach (Chang et al., 2011). Re-examining CSFs (Ram et al., 2013) along ERP lifecycle in SMEs (Shaul and Tauber, 2012). Revising application of ERP systems to healthcare (Stapleton, 2006). New look to sustainable ERP (Chofreh et al., 2014).

Note: References in the list above are part of sample papers which can be obtained by e-mailing: farzanakhoory@gmail.com

On the other hand, revising topics include: revising ERP implementation using a KM perspective, expanding ERP implementations to include VAT compliance, revising ERP implementation success in post-implementation organizational contexts, 
JEIM 29,6

re-examining the Delone-McLean IS success model to study ERP success, a new look at the determinants of the firm's readiness to implement an ERP, re-examining CSFs along ERP lifecycle in SMEs, revising of ERP implementations from the perspective of globalization side effects, revising application of ERP systems to healthcare, and a new look to sustainable ERP (see list (ERP intellectual contributions: envisioning type)).

\subsection{Explicating ERP contributions}

Delineating in ERP research received great attention from researchers and practitioners. The coverage of delineating in the ERP research topics include general aspects of ERP systems such as data quality, hidden financial costs of ERP, ERP compliance, future of ERP in internet economy, ERP project risks, and role of ERP in system security, selection, implementation and use aspects of ERP systems such as, selection process in midsize and large organizations and in made-to-order SME sector, selection of ERP suppliers, organizing ERP post-implementation, alignment of ERP implementation in a newly established firm, exploring the role of post-implementation learning in ERP usage, benefits, success, and failure aspects of ERP systems such as explaining long-term ERP success, implementation factors that influence the ERP benefits, the influences of external expertise and in-house computer/IT knowledge on ERP system success and analysis of failed ERP projects, impact of ERP systems such as impact on management control systems, organizational capabilities, operational performance, firm performance, on work, work-life, role of accountants, production-sales interface.

Coverage of summarizing include topics such as an integrative review of ERP systems, summarization of ERP tools in supply chain information sharing, review of factors and methods for integrating heterogeneous ERP systems, and review of ERP socio-technical challenges, a review of ERP integration in a healthcare environment, a conceptual framework for ERP II, a conceptual framework for investigation impact of human inputs on ERP implementation effectiveness, and a comprehensive framework for evaluating ERP systems (intellectual contributions in ERP: explicating type):

(1) Delineating (45 percent)

- Sample of topics:

- General aspects of ERP systems: ERP system data quality (Haug et al., 2009). Explaining ERP compliance with Sarbanes-Oxley (SOX) act (Brown and Nasuti, 2005). Defining value-based objectives for ERP systems planning (May et al., 2013). Understanding the moderating role of ERP in system security (Bradford et al., 2014). Investigating the best methods for preventing new coding defects in ERP (Woungang et al., 2012). Exploring the rationales for customization in SEMs (Zach and Munkvold, 2012). ERP systems' capabilities for SCM performance (Forslund, 2010). The hidden financial costs of ERP (Lindley et al., 2008). Delineating the ERP institutionalization process (Maheshwari et al., 2010). Discussing the future of ERP in internet economy (Hayman, 2000).

- Selection, implementation, and use: ERP selection process in midsize and large organizations (Bernroider and Koch, 2001) and in made-to-order SME sector (Deep et al., 2008). Selection of ERP suppliers using AHP tools (Wei et al., 2005). Prioritization ERP evaluation criteria (Méxas et al., 2012). Interpreting an ERP-implementation project from a stakeholder perspective (Boonstra, 2006), user's perspective (Amoako-Gyampah, 2007) 
and internet-based grounded theory approach (Oliver et al., 2005). Organizing ERP post-implementation using contingency theory perspective (Gallagher and Gallagher, 2012). The use of ERP in assessing the adherence to lean manufacturing in SEMs (Iris and Cebeci, 2014). Implementation of ERP system within a large manufacturing organization (Yusuf et al. (2004). Planning ERP acquisition (Verville and Halingten, 2002a; Verville et al., 2007).

- Benefits, success, failure, and risk: explaining long-term ERP success (Häkkinen and Hilmola, 2008b). Implementation factors that influence the ERP benefits (Chou and Chang, 2008). Evaluating the value-added benefits of using requirements reuse metrics in ERP projects (Daneva, 2001). Benefits realization road-map framework for ERP usage in SMEs (Esteves, 2009). The impact of enterprise systems on corporate performance (Hendricks et al., 2007). Exploring how enterprises generate business value from ERP investments (Ross and Vitale, 2000). Investigation of the relationships between organizational factors, business process improvement, and ERP success (Law and Ngai, 2007). omprehensive analysis of failed ERP projects (Garg and Garg, 2013).

- Impact of ERP: impact of ERP on job content (Benders et al., 2009) work, work-life (Wickramasinghe and Karunasekara, 2012), role of accountants (Chen et al., 2012), and production-sales interface (de Vries and Boonstra, 2012). Impact of business process management and some CSFs on successful ERP implementations (Žabjek et al., 2009).

(2) Summarizing (6 percent)

- Sample of topics:

- A review of state of the art ERP research (Nazemi et al., 2012; Robert Jacobs, 2007). A conceptual framework for ERP II (Møller, 2005). An integrative review of ERP systems (Shehab et al., 2004). Overview of ERP along its real implementation (Gupta, 2000). Survey of ERP in manufacturing firms (Olhager and Selldin, 2003). Prospective overview of the role of ERP for marketing processes (Gardiner et al., 2002). Summarization of ERP tools in supply chain information sharing (Kelle and Akbulut, 2005). Review of critical issues in ERP (Al-Mashari, 2001). ERP data sharing framework for product lifecycle management (Naciri et al., 2011). Hybrid methodology for ERP system selection (Kilic et al., 2014). A conceptual framework for investigation impact of human inputs on ERP implementation effectiveness (Maditinos et al., 2011).

Note: References in the list above are part of sample papers which can be obtained by e-mailing: farzanakhoory@gmail.com

\subsection{Relating ERP contributions}

Differentiating research coverage includes topics such as: people dimension of ERP systems such as, comparing end-user and managerial perspectives of ERP implementation factors, comparative empirical analysis of ERP vendors and customers, differentiating manager and end-user perspectives regarding CSFs for ERP implementation, contrasting 
JEIM 29,6

932 consultant and vendor views of expectation and the reality of ERP implementation, implementation, and use aspects of ERP systems such as, national differences in ERP implementations, comparison of BPR implementation approaches, comparing ERP system strategies for companies in parent-subsidiary supply chains, and benefits, value, and performance aspects of ERP systems such as, contrasting benefits of SAP vs Oracle package, differentiating between ERP use and ERP value in SMEs, contrasting workflow systems and ERP systems, contrasting between ERP, balanced scorecard, and IT (intellectual contributions in ERP: relating type):

(1) Differentiating (6 percent)

- Sample of topics:

- People dimension: comparison of end-user and managerial perspectives of ERP implementation factors (Amoako-Gyampah, 2004). Comparative empirical analysis of ERP vendors and customers (Watanabe and Hobo, 2004). Differentiating manager and end-user perspectives regarding CSFs for ERP implementation (Lin and Rohm, 2009). Differentiating between stakeholder perspectives regarding communication strategies during change management (Finney, 2011).

- Implementation, and use: comparison of BPR implementation approaches (Huq and Martin, 2006). National differences in ERP implementations (Sheu et al., 2004). Comparing use of ERP systems in the service sector (Botta-Genoulaz and Millet, 2006). Comparing ERP system strategies for companies in parent-subsidiary supply chains (Haug et al., 2010).

- Benefits, value, and performance: contrasting benefits of SAP vs Oracle package (Annamalai and Ramayah, 2011). Segmenting and mining the ERP users' perceived benefits (Wu, 2011). Comparing the importance of evaluation criteria in proprietary and open-source enterprise of ERP and Office systems (Benlian and Hess, 2011). Differentiating between ERP use and ERP value in SMEs (Ruivo et al., 2012, 2014). Comparing firm performance of ERP adopters and non-adopters (Hunton et al., 2003). Contrasting workflow systems and ERP systems (Cardoso et al., 2004).

(2) Integrating (7 percent)

- Sample of topics:

- Selection, adoption, implementation, and maintenance: integrating Analytic Network Process (ANP) into the ERP selection (Percin, 2008). Integrating hybrid multi-criteria decision making model for ERP selection (Gürbüz et al., 2012). Relating real-option analysis framework to valuation and investment decisions for ERP projects (Wu et al., 2009). Relating business strategies to ERP adoption (Jang et al., 2009). Integrating project management factors in ERP implementation (Chien et al., 2007). Relating SCM performance to ERP implementation (Yang and Su, 2009). Integrating data management, software configuration management, and CRM to facilitate ERP maintenance (Jansen et al., 2006).

- Integrating ERPs with other systems: integrating KM and ERP systems (Liu, 2011). Integrating of environmental information within ERP systems (Lamber $e t$ al., 2000). Data integration between product data management 
and ERP for global manufacturing (Lee et al., 2011). Integrating multiaspectual understanding for ERP success evaluation (Jahanyan et al., 2012). Integrating ERP and material flow cost accounting systems for improving waste-reduction decisions (Michael and van der Poll, 2012).

- People dimension: integrating marketing and ERP implementation ideas and strategies to overcome workers' resistance to ERP (Aladwani, 2001). Integrating literature on technology acceptance, readiness for change, and change implementation of students' readiness to use ERP (Shivers-Blackwell and Charles, 2006). Integrating task interdependence and cultural norms in shaping supervisory views of ERP systems (Bendoly et al., 2006).

Note: References in the list above are part of sample papers which can be obtained by e-mailing: farzanakhoory@gmail.com

Integrating research includes topics such as: selection, adoption, implementation, and maintenance aspect of ERP systems such as, integrating project management factors in ERP implementation, integrating data management, software configuration management, and CRM to facilitate ERP maintenance, integrating ANP into the ERP selection, integrating change management into ERP implementation, and relating SCM performance to ERP implementation, integrating ERPs with other systems such as, integrating $\mathrm{KM}$ and ERP systems, integrating ERP systems in lean implementation process, integrating of environmental information within ERP systems, and people dimension of ERP systems such as, integrating marketing and ERP implementation ideas and strategies to overcome workers' resistance to ERP, integrating task interdependence and cultural norms in shaping supervisory views of ERP systems (see list (intellectual contributions in ERP: relating type)).

\subsection{Debating ERP contributions}

Advocating research covers topics such as advocating open sources ERPs for SMEs, advocating process visibility for realizing the full ERP potential, advocating for human actions beyond human agency, advocating for incorporating ERP and KM systems for fostering efficiency and innovation, emphasizing the competitive advantage of ERP systems, and emphasizing the positive impact and strategic advantages of ERP systems (intellectual contributions in ERP: debating type):

(1) Advocating (3 percent):

- Advocating process visibility for realizing the full ERP potential (Beretta, 2002). Positive impact of ERP systems on firm competencies in SCM (Su and Yang, 2010). Implementing ERP and KM systems for fostering efficiency and innovation (Newell et al., 2003). Emphasizing the strategic and competitive advantage of ERP systems (Ram et al., 2014b). Reductionism and complex thinking during ERP implementations for understanding business transformational processes (Wood and Caldas, 2001). Advocating for human actions beyond human agency (Kallinikos, 2004). Advocating open sources ERPs for SMEs (Johansson and Sudzina, 2008).

(2) Refuting (2 percent):

- ERP systems are far from sufficient to promote a strong competitive position over the long-term (Lengnick-Hall et al., 2004). Questioning ERP systems ability to provide competitive advantage (Ragowsky and Gefen, 2008).The 
JEIM

29,6

934

extensive organizational investments in shaping pre-implementation attitudes do always achieve the desired effects for ERP implementation (Abdinnour-Helm et al., 2003). Refuting the idea that consensus must be sought between ERP vendor and client in instances of conflict if success is to be realized (Wagner and Newell, 2006). The integrative nature of ERP systems is a key factor of their failures (Morton and Hu, 2008). Refuting ERP solution for SMEs and suggesting a non-IT ERP solution (Sen and Bhattacharya, 2008).

Note: References in the list above are part of sample papers which can be obtained by e-mailing: farzanakhoory@gmail.com

Refuting topics include discussing the insufficiency of ERP systems for promoting a strong competitive position over the long-term, questioning ERPs integration ability in socially disintegrated enterprises, arguing that the integrative nature of ERP systems is a key factor of their failures, questioning ERP systems ability to provide competitive advantage, and refuting ERP solution for SMEs and suggesting a non-IT ERP solution (see list (intellectual contributions in ERP: debating)).

It is clear that not all types of ERP knowledge as expressed by the MacInnis framework sub-types have had equal attention by ERP researchers. For instance, advocating and refuting received little attention and may represent a research opportunity for ERP academics and professionals. A question that comes to mind is whether coverage of such types of knowledge grows with the maturity of the topic of discussions. If so, the relatively scant coverage of debating and refuting makes sense in the case of ERP systems as they are still relatively new. However, this may be a question for future inquiry. Similar opportunities appear to exist in the areas of differentiating and integrating. For example, are there any distinguishing characteristics between the major ERP systems that may make one system a better fit for a specific industry type, organization size, culture, or structure?

\subsection{MacInnis and March-Smith frameworks: parallelism and complementarity}

In MacInnis framework, a conceptualization is "a process of abstract thinking involving the mental representation of an idea," and thus conceptual contributions are of abstract (non-empirical) nature. To complement the heavier conceptual emphasis and lighter empirical emphasis of MacInnis framework, we recall the work of March and Smith (1995). One can see parallels between MacInnis framework and that of March and Smith (1995), and derive additional insights on ERP intellectual contributions. March and Smith framework is driven by the distinction between research activities (build, evaluate, theorize, and justify) and outputs/artifacts (constructs, models, methods, and instantiations). Whereas the build activity of March and Smith can be mapped to the envisioning and explicating types of MacInnis, the evaluate activity can be mapped to the relating and debating types of MacInnis (Figure 2). According to March and Smith, IT research focuses on building and evaluating constructs, models, methods, and instantiations; and, also on theorizing about these artifacts and attempting to justify these theories. Looking at ERP intellectual contributions from March and Smith's build-evaluate lens, one would expect that these contributions would focus more on the evaluate activity (identification of usefulness of the system to the enterprise) than on the build activity, because ERP systems are generally off-the-shelf pre-built software packages. Exceptions include authors (such as Parthasarathy and Sharma, 2014; Zach and 


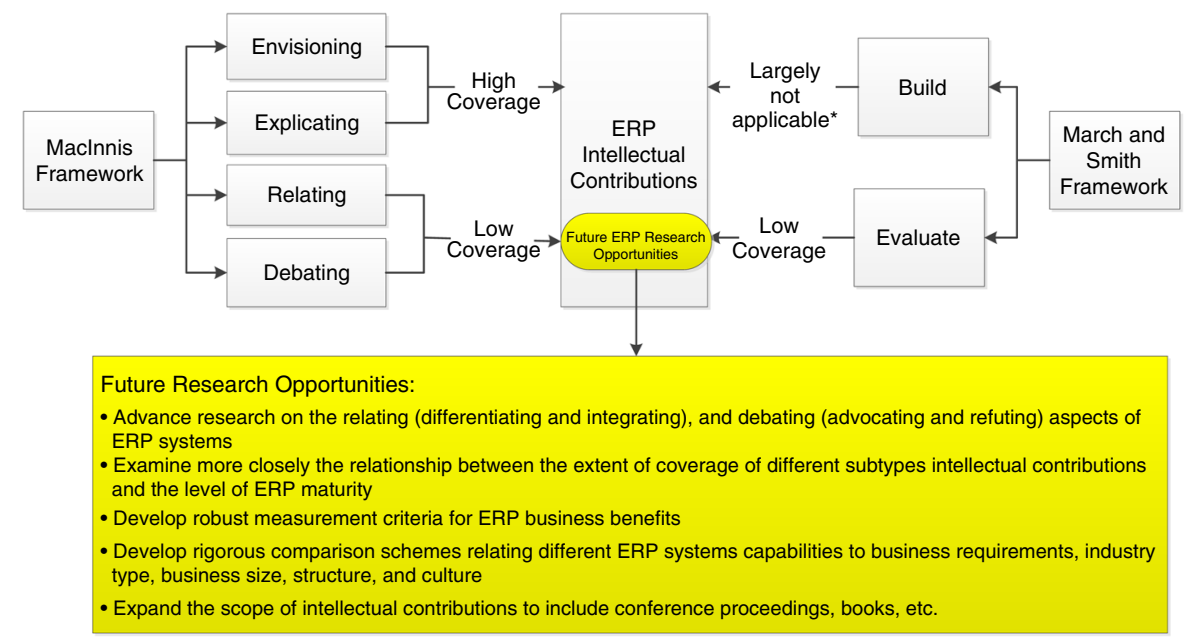

Note: *ERP systems are off-the-shelf software packages

\section{Organizing ERP research}

935

Figure 2.

Integration of analytical frameworks: current coverage and future opportunities of ERP research

Munkvold, 2012) who discussed ERP customization to build or modify functionality to fit specific enterprise needs. However, our findings indicate that evaluating was not an overwhelming ERP research focus as would have been predicted by March and Smith framework. One possible explanation of such incongruence is that ERP impact (and business benefits) is a complex topic in its own right, particularly in scope and measurement, and that the perceived and realized benefits of ERP implementation are different and difficult to define (Hsu and Chen, 2004), and that the dimensions of ERP benefits are interconnected, and their realization is a continuum along the ERP postimplementation axis (Esteves, 2009).

While Hsu and Chen (2004) and Annamalai and Ramayah (2011) highlighted the need for distinguishing between tangible and intangible ERP benefits, Häkkinen and Hilmola (2008b) discussed the need to address the distinction between short-term and long-term benefits. Furthermore, Esteves (2009), Federici (2009), and Kale et al. (2010), focused specifically on ERP benefits within the context of SMEs. It is also important to clearly distinguish between ERP systems system-benefits and ERP systems business benefits. Some authors (Akkermans et al., 2003; Yang and Su, 2009; Su and Yang, 2010) addressed the business benefits of ERP systems from a SCM perspective, others (Saatçioglu, 2009; Wu, 2011; Jahanyan et al., 2012) identified the most important ERP benefits from a user satisfaction perspective. Yet other researchers examined ERP impact on financial performance of adopter and non-adopter firms (Romero et al., 2010), early adopter and late-adopter firms (Hendricks et al., 2007), adopters firms' with early changes and revision to ERP (Nicolaou and Bhattacharya, 2006). Kallunki et al. (2011) reported on the impact of ERP systems on a firm nonfinancial performance. Along the same lines, Bendoly and Schoenherr (2005) examined impact of the length of time ERP systems have been in use on maintenancerepair-operating savings that a firm enjoys. Mabert et al. (2003) and Staehr (2010) reported that different ERP business benefits can be achieved by organizations of different sizes. At a more strategic level, Ram et al. (2014) explored the role of ERP in achievement of competitive advantage. 
JEIM 29,6

936

In addition to aforementioned examination of the multiple dimensions of ERP benefits, assessing ERP usefulness effectively calls for developing measurement criteria, both quantitative and qualitative, and exploring if these criteria vary across different industry sectors (O'Leary, 2004), different enterprise sizes (Mabert et al., 2003), and different managerial levels (Staehr, 2010). Our analysis identified measurement criteria of ERP benefits as an area that has received scant attention from ERP researchers, and, we believe, addressing this aspect will lead to better grasp of ERP benefits. Another area that did not receive enough attention is a robust comparison between the major ERP systems and not to treat them as equals or depend on vendor comparisons which are usually meant for selling than for academic purposes, and are not necessarily readily available to the academic community. Thus the need for more research emphasis on inter-ERP-system relating-type contributions, per MacInnis framework, to provide a more objective view, understanding, and to enable better fit (Hong and Kim, 2002) between an ERP system and the enterprise needs, given that lack of such fit is a well-documented risk factor for ERP project failure. Furthermore, our analysis also reveals that existing ERP research does not shed much light on whether there is a universal set of criteria for ERP benefits evaluation, or if there are industryspecific such criteria, or if there is a mix of universal and industry-specific criteria.

\section{Conclusions, limitation, and future directions}

ERP systems are so far the most comprehensive business ISs that have come into existence, and consequently are the most researched type of enterprise ISs. This paper attempts to classify ERP intellectual contributions using MacInnis framework that was originally developed to classify conceptual contributions in marketing. The framework provides four generic types of conceptual contributions, each of which has two specific sub-types. Using MacInnis framework provides a systematic and knowledge-centric approach to classifying ERP intellectual contributions. The analysis highlighted ERP themes that are well researched, and identified themes that received little attention from researchers. Specifically (Figure 2):

- ERP topics that are highly researched mainly focused on envisioning and explicating, an empirical finding that well matches the fact that ERP systems are relatively new and thus many aspects need to be initially identified and revised. Furthermore, ERP systems are very complex and multidimensional and thus require a great deal of delineating and summarizing.

- The analysis also revealed that there appears to be a temporal dimension of the various types of ERP intellectual contributions. Researchers start with envisioning a scientific phenomenon which is then followed by explicating (particularly if the subject of discussion is complex, such as the case of ERP systems), then the contributions move to a higher level of discourse, namely, relating the concept to other concepts, and possibly concurrently to or following relating, the discourse moves to debating the value of the topic that has been envisioned, explicated, and related. In fact, while explicating and relating exhibit an upward trend over time, envisioning and debating show significant drops during the last five-year time interval (2010-2014). This is an observation that deserves further investigation.

- The low coverage of relating in the ERP literature seems to be a consequence of the uniqueness of these systems as they are not like other ISs in terms of their 
significance, cost, complexity, and potential. Further research to relate various ERP systems might be of significant value to practitioners in identifying the ERP system that best fits their business needs.

- From the low coverage of debating, it appears that there is some kind of overall consensus between researchers' conceptualizations of ERP systems, whether these conceptualizations were positive (advocating) or negative (refuting).

- Evaluating activity (identification of usefulness of the systems to business) was not an overwhelming ERP research focus as March and Smith framework would have predicted.

The main limitation of this research is that it only focused on a sample of papers published in scholarly journals, and did not cover conference proceedings, books, and other types of intellectual contributions. Another limitation is that the search criteria were title-based, which may have led to missing some papers that discuss ERP, but do not use ERP or "Enterprise Resource Planning" in their title. Some papers may fall into more than one category and we believe that this is one of the limitations of MacInnis framework.

Future research is needed to address the aspects of ERP systems that have not received much attention so far, such as debating and relating; further inquire whether there is a relationship between the extents of coverage of the different sub-types of intellectual contributions and the level of maturity of the IS that is the subject of intellectual discussion; address similar opportunities that exist in the areas of differentiating and integrating; for example, are there any distinguishing characteristics between the major ERP systems that may make one system a better fit for a specific industry type, organization size, culture, or structure?; develop robust measurement criteria for ERP benefits which, we believe, will lead to better grasp of ERP business benefits; develop rigorous comparison scheme between the major ERP systems to improve better fit between the system and the business requirements; and expand the analysis to include other types of ERP intellectual contributions such as conference proceedings.

\section{References}

Akkermans, H.A., Bogerd, P., Yücesan, E. and Van Wassenhove, L.N. (2003), “The impact of ERP on supply chain management: exploratory findings from a European Delphi study", European Journal of Operational Research, Vol. 146 No. 2, pp. 284-301.

Al-Mudimigh, A., Zairi, M. and Al-Mashari, M. (2001), "ERP software implementation: an integrative framework", European Journal of Information Systems, Vol. 10 No. 4, pp. 216-226.

Aloini, D., Dulmin, R. and Mininno, V. (2007), "Risk management in ERP project introduction: review of the literature", Information \& Management, Vol. 44 No. 6, pp. 547-567.

Annamalai, C. and Ramayah, T. (2011), "Enterprise resource planning (ERP) benefits survey of Indian manufacturing firms: an empirical analysis of SAP versus Oracle package", Business Process Management Journal, Vol. 17 No. 3, pp. 495-509.

Bendoly, E. and Schoenherr, T. (2005), "ERP system and implementation-process benefits: implications for B2B e-procurement", International Journal of Operations and Production Management, Vol. 25 No. 4, pp. 304-319.

Botta-Genoulaz, V., Millet, P.A. and Grabot, B. (2005), "A survey on the recent research literature on ERP systems", Computers in Industry, Vol. 56 No. 6, pp. 510-522. 
JEIM

29,6

938
Cumbie, B.A., Jourdan, Z., Peachy, T., Dugo, T.M. and Craighead, C.W. (2005), "Enterprise resource planning research: where are we now and where should we go from here?", Journal of Information Technology Theory and Application, Vol. 7 No. 2, pp. 21-36.

Davenport, T.H. (2000), Mission Critical: Realizing the Promise of Enterprise Systems, Harvard Business Press, Boston, MA, pp. 7-9.

Dillon, C. (1999), Stretching Toward Enterprise Flexibility with ERP Apics - The Performance Advantage, Vol. 10, pp. 38-43.

Esteves, J. (2009), "A benefits realization road-map framework for ERP usage in small and medium-sized enterprises", Journal of Enterprise Information Management, Vol. 22 Nos 1/2, pp. 25-35.

Esteves, J. and Bohorquez, V. (2007), "An updated ERP systems annotated bibliography: 2001-2005", Communications of the Association for Information Systems, Vol. 19 No. 18, pp. 386-446.

Esteves, J. and Pastor, J. (2001), "Enterprise resource planning systems research: an annotated bibliography", Communications of the Association for Information Systems, Vol. 7 No. 8, pp. 1-51.

Federici, T. (2009), "Factors influencing ERP outcomes in SMEs: a post-introduction assessment", Journal of Enterprise Information Management, Vol. 22 Nos 1/2, pp. 81-98.

Gupta, A. (2000), "Enterprise resource planning: the emerging organizational value systems", Industrial Management and Data Systems, Vol. 100 No. 3, pp. 114-118.

Häkkinen, L. and Hilmola, O.P. (2008), "Life after ERP implementation: long-term development of user perceptions of system success in an after-sales environment”, Journal of Enterprise Information Management, Vol. 21 No. 3, pp. 285-310.

Hendricks, K.B., Singhal, V.R. and Stratman, J.K. (2007), "The impact of enterprise systems on corporate performance: a study of ERP, SCM, and CRM system implementations", Journal of Operations Management, Vol. 25 No. 1, pp. 65-82.

Hong, K.K. and Kim, Y.G. (2002), "The critical success factors for ERP implementation: an organizational fit perspective", Information and Management, Vol. 40 No. 1, pp. 25-40.

Hossain, L., Patrick, J.D. and Rashid, M.A. (2002), Enterprise Resource Planning: Global Opportunities and Challenges, IGI Global, Hershey, PA, pp. 4-6.

Hsu, L.L. and Chen, M. (2004), "Impacts of ERP systems on the integrated-interaction performance of manufacturing and marketing", Industrial Management and Data Systems, Vol. 104 No. 1, pp. 42-55.

Jahanyan, S., Azar, A. and Fard, H.D. (2012), "Utilizing multi-aspectual understanding as a framework for ERP success evaluation: a case study", Journal of Enterprise Information Management, Vol. 25 No. 5, pp. 479-504.

Kale, P.T., Banwait, S.S. and Laroiya, S.C. (2010), "Performance evaluation of ERP implementation in Indian SMEs", Journal of Manufacturing Technology Management, Vol. 21 No. 6, pp. 758-780.

Kallunki, J.P., Laitinen, E.K. and Silvola, H. (2011), "Impact of enterprise resource planning systems on management control systems and firm performance", International Journal of Accounting Information Systems, Vol. 12 No. 1, pp. 20-39.

MacInnis, D.J. (2011), “A framework for conceptual contributions in marketing”, Journal of Marketing, Vol. 75 No. 4, pp. 136-154.

Mabert, V.A., Soni, A. and Venkataramanan, M.A. (2003), "The impact of organization size on enterprise resource planning (ERP) implementations in the US manufacturing sector", Omega, Vol. 31 No. 3, pp. 235-246. 
Mandal, P. and Gunasekaran, A. (2003), "Issues in implementing ERP: a case study", European Journal of Operational Research, Vol. 146 No. 2, pp. 274-283.

March, S.T. and Smith, G.F. (1995), "Design and natural science research on information technology", Decision Support Systems, Vol. 15 No. 4, pp. 251-266.

Moon, Y.B. (2007), "Enterprise resource planning (ERP): a review of the literature", International Journal of Management and Enterprise Development, Vol. 4 No. 3, pp. 235-264.

Murray, M. and Coffin, G. (2001), "A case study analysis of factors for success in ERP system implementations", Proceedings of the Seventh Americas Conference on Information Systems (AMCIS), pp. 1012-1018.

Nicolaou, A.I. and Bhattacharya, S. (2006), "Organizational performance effects of ERP systems usage: the impact of post-implementation changes", International Journal of Accounting Information Systems, Vol. 7 No. 1, pp. 18-35.

O'Leary, D.E. (2004), "Enterprise resource planning (ERP) systems: an empirical analysis of benefits", Journal of Emerging Technologies in Accounting, Vol. 1 No. 1, pp. 63-72.

Parthasarathy, S. and Sharma, S. (2014), "Determining ERP customization choices using nominal group technique and analytical hierarchy process", Computers in Industry, Vol. 65 No. 6, pp. 1009-1017.

Ram, J., Wu, M.L. and Tagg, R. (2014), "Competitive advantage from ERP projects: examining the role of key implementation drivers", International Journal of Project Management, Vol. 32 No. 4, pp. 663-675.

Romero, J.A., Menon, N., Banker, R.D. and Anderson, M. (2010), "ERP: Drilling for profit in the oil and gas industry", Communications of the ACM, Vol. 53 No. 7, pp. 118-121.

Ross, J.W. and Vitale, M.R. (2000), "The ERP revolution: surviving vs thriving”, Information Systems Frontiers, Vol. 2 No. 2, pp. 233-241.

Saatçioglu, Ö.Y. (2009), "What determines user satisfaction in ERP projects: benefits, barriers or risks?", Journal of Enterprise Information Management, Vol. 22 No. 6, pp. 690-708.

Schlichter, B.R. and Kraemmergaard, P. (2010), "A comprehensive literature review of the ERP research field over a decade", Journal of Enterprise Information Management, Vol. 23 No. 4, pp. 486-520.

Scott, J.E. and Vessey, I. (2000), "Implementing enterprise resource planning systems: the role of learning from failure", Information Systems Frontiers, Vol. 2 No. 2, pp. 213-232.

Shehab, E.M., Sharp, M.W., Supramaniam, L. and Spedding, T.A. (2004), "Enterprise resource planning: an integrative review", Business Process Management Journal, Vol. 10 No. 4, pp. 359-386.

Skok, W. and Legge, M. (2002), "Evaluating enterprise resource-planning (ERP) systems using an interpretative approach", Knowledge and Process Management, Vol. 9 No. 2, pp. 72-82.

Staehr, L. (2010), "Understanding the role of managerial agency in achieving business benefits from ERP systems”, Information Systems Journal, Vol. 20 No. 3, pp. 213-238.

Su, Y.F. and Yang, C. (2010), "A structural equation model for analyzing the impact of ERP on SCM”, Expert Systems with Applications, Vol. 37 No. 1, pp. 456-469.

Tsai, W.H., Lee, P.L., Shen, Y.S. and Lin, H.L. (2012), “A comprehensive study of the relationship between enterprise resource planning selection criteria and enterprise resource planning system success", Information \& Management, Vol. 49 No. 1, pp. 36-46.

Umble, E.J., Haft, R.R. and Umble, M.M. (2003), "Enterprise resource planning: implementation procedures and critical success factors", European Journal of Operational Research, Vol. 146 No. 2, pp. 241-257. 
JEIM

29,6

940

Volkoff, O. (1999), "Using the structurational model of technology to analyze an ERP implementation", Proceedings of AMCIS, pp. 235-237.

Wu, J.H. and Wang, Y.M. (2007), "Measuring ERP success: the key-users' viewpoint of the ERP to produce a viable IS in the organization", Computers in Human Behavior, Vol. 23 No. 3, pp. 1582-1596.

Wu, W.W. (2011), "Segmenting and mining the ERP users' perceived benefits using the rough set approach”, Expert Systems with Applications, Vol. 38 No. 6, pp. 6940-6948.

Yadav, M.S. (2010), "The decline of conceptual articles and implications for knowledge development", Journal of Marketing, Vol. 74 No. 1, pp. 1-19.

Yang, C. and Su, Y.F. (2009), "The relationship between benefits of ERP systems implementation and its impacts on firm performance of SCM", Journal of Enterprise Information Management, Vol. 22 No. 6, pp. 722-752.

Zach, O. and Munkvold, B.E. (2012), "Identifying reasons for ERP system customization in SMEs: a multiple case study", Journal of Enterprise Information Management, Vol. 25 No. 5, pp. $462-478$.

\section{Further reading}

Ram, J. and Corkindale, D. (2014), "How "critical"” are the critical success factors (CSFs)? Examining the role of CSFs for ERP”, Business Process Management Journal, Vol. 20 No. 1, pp. 151-174.

\section{Corresponding author}

Adam Fadlalla can be contacted at: fadlalla@qu.edu.qa

For instructions on how to order reprints of this article, please visit our website:

www.emeraldgrouppublishing.com/licensing/reprints.htm

Or contact us for further details: permissions@emeraldinsight.com 